
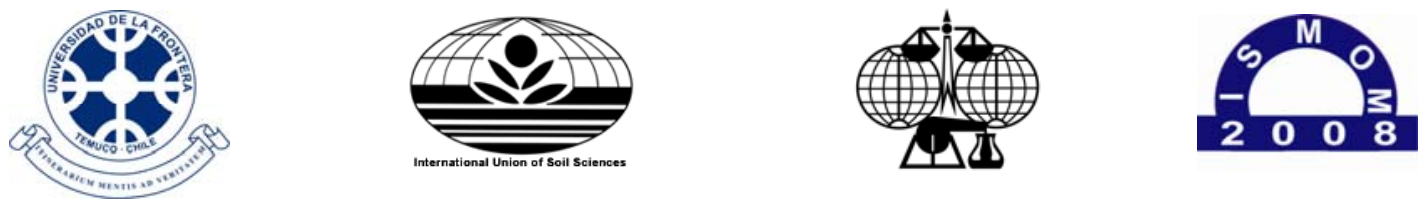

$5^{\text {th }}$ International Symposium ISMOM 2008 - November $24^{\text {th }}-28^{\text {th }}, 2008$ - Pucón, Chile

Keynote papers

\title{
K-2
}

\section{Use of Nanoparticles in Soil-Water Bioremediation Processes}

\author{
N. Durán* \\ Instituto de Química, Biological Chemistry Laboratory, Universidade Estadual de Campinas, C.P. \\ 6154, Campinas, CEP 13083-970,S.P., Brazil.*E-mail:duran@iqm.unicamp.br
}

\section{Introduction}

As a general definition, nanotechnology is involved with objects on the nano scale, or materials measuring between 1 and $100 \mathrm{~nm}$. It was found a good definition that is practical and unconstrained by any arbitrary size limitations: The design, characterization, production, and application of structures, devices, and systems by controlled manipulation of size and shape at the nanometer scale that produces structures, devices, and systems with at least one novel/superior characteristic or property (Bawa et al., 2005). Nanotechnology has contributed to the development of a great diversity of materials as those used in electronic, optoelectronic, biomedical, pharmaceutical, cosmetic, energy, catalytic, and materials applications. In the manufacturing community, the most profitable trail for nanoscale particles and materials have been in the areas of sunscreen, magnetic recording tape, automotive catalyst supports, biolabeling, chemical-mechanical polishing, electroconductive coatings, and optical fibers. However, the emergence of nanotechnology presents a number of potential environmental benefits. This potential impact area could be divided into three categories: treatment and remediation, sensing and detection, and pollution prevention. Some nanoparticles destroy contaminants, for instance, while others sequester them. The specific nanotechnologies that it will be discussed hereafter focus on site remediation and waste water treatment. Besides the applications for soil, groundwater, and wastewater, a number of nanotechnologies for air remediation are also in development. Carbon nanotubes, for example, have been recognized for their ability to adsorb dioxin much more strongly than traditional activated carbon. Smaller particle size enables the development of smaller sensors, which can be deployed more easily into remote locations. The ability of nanotechnology to abate pollution production is in progress and could potentially catalyze the most revolutionary changes in the environmental field (Watlington, 2005).

\section{Some Uses of Nanotechnology}

\section{Nano iron and its derivatives}

Remediation has grown and evolved, continually developing and adopting new technologies and improving the remediation process. One of the most established systems is that termed "pump-and-treat". Pump-and-treat systems operate on the basis of removing contaminated groundwater from the ground, downstream of the contamination site, and then treating it before returning it to the ground. This technology it takes a long time to achieve cleanup goals and it is expensive to operate and maintain. 

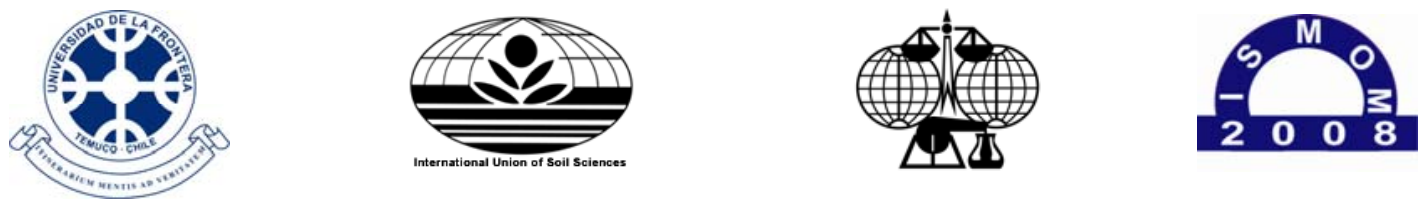

$5^{\text {th }}$ International Symposium ISMOM 2008 - November $24^{\text {th }}-28^{\text {th }}, 2008$ - Pucón, Chile

\section{Keynote papers}

Reducing capabilities of metallic substances, such as zero-valent iron (ZVI), were examined for their ability to treat a wide range of contaminants in hazardous wastewater. The most common use of ZVI has been in the form of permeable reactive barriers (PRBs) designed to intercept plumes in the subsurface and subsequently remediate them. However, new technologies are now available to compete with PRBs. Nanoscale iron particles and their derivatives offer more alternatives to many remediation technologies. The small particle size of the nano iron (1-100 nm) facilitates a high level of remedial versatility. This allows a much greater diversity in applications as compared to the traditional ZVI employed in PRBs. Nanoscale Zero Valent Iron (nZVI) and Reactive Nanoscale Iron Product (RNIP) are the most basic form of the nano iron technology (Watlington, 2005). Table 1 lists many of the pollutants potentially remediated by nano iron (Zhang, 2003).

Table 1. Pollutants remediated by nano iron technology

\begin{tabular}{|c|c|c|}
\hline Carbon tetrachloride & Chrysoidine & cis-Dichloroethene \\
\hline Chloroform & Tropaeolin & trans-Dichloroethene \\
\hline Dichloromethane & Acid Orange & 1.1-Dichloroethene \\
\hline Chloromethane & Acid Red & Vinyl Chloride \\
\hline Hexachlorobenzene & Mercury & PCBs \\
\hline Pentachlorobenzene & Nickel & Dioxins \\
\hline Tetrachlorobenzenes & Silver & Pentachlorophenol \\
\hline Trichlorobenzenes & Cadmium & NDMA \\
\hline Dichlorobenzenes & Bromoform & TNT \\
\hline Chlorobenzene & Dibromochloromethane & Dichromate \\
\hline DDT & Dichlorobromomethane & Arsenic \\
\hline Lindane & Tetrachloroethene & Perchlorate \\
\hline Orange II & Trichloroethene & Nitrate \\
\hline
\end{tabular}

\section{Dendrimers}

Dendritic polymers, which include random hyperbranched polymers, dendrigraft polymers, dendrons and dendrimers, are relatively monodispersed and highly branched macromolecules with controlled composition and architecture consisting of three components: a core, interior branch cells and terminal branch cell (Savage and Diallo, 2005).

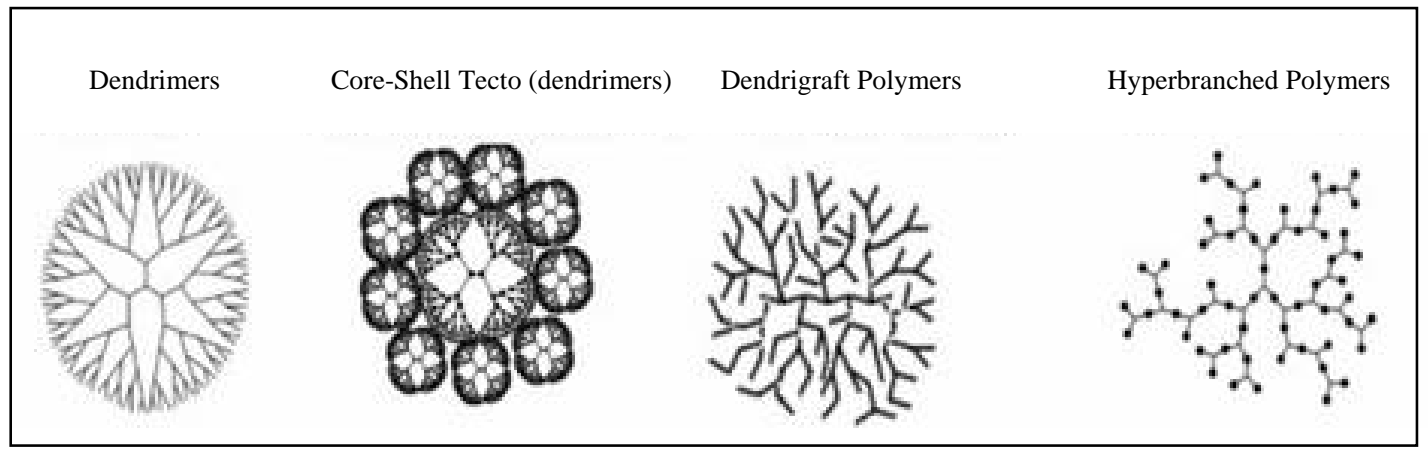

Figure 1. Dendritic polymers 

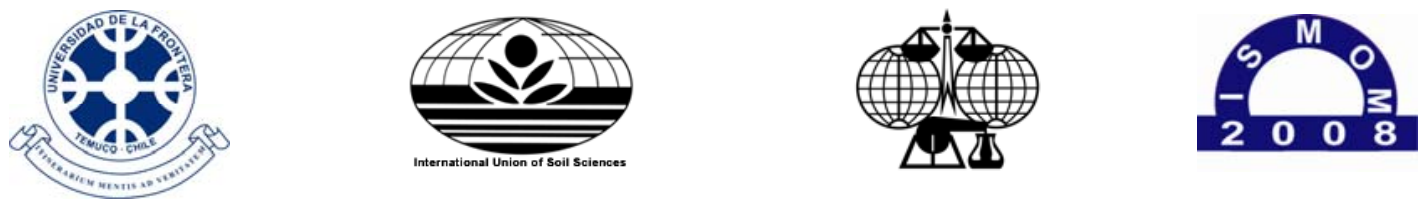

$5^{\text {th }}$ International Symposium ISMOM 2008 - November $24^{\text {th }}-28^{\text {th }}, 2008$ - Pucón, Chile

Keynote papers

Diallo's group proposed process consisting of a clean water recovery unit and a dendrimer recovery unit can be seen below in Figure 1. Diallo et al. (2005) are currently working on the engineering development of this process with hopes of having pilot-scale demonstration in the next years (Figure 2). The development of a method that permits removal of organic pollutants by employing a simple filtration step has been described by Arkas et al. (2006). This was pursued by utilizing titanium dioxide $\left(\mathrm{TiO}_{2}\right)$ porous ceramic filters of which the pores were impregnated with an alkylated poly(propylene imine) dendrimer, poly(ethylene imine) hyperbranched polymer or $\beta$ cyclodextrin, thus resulting in hybrid organic/inorganic filter modules of high mechanical strength and high surface area (Diallo, 2005) .

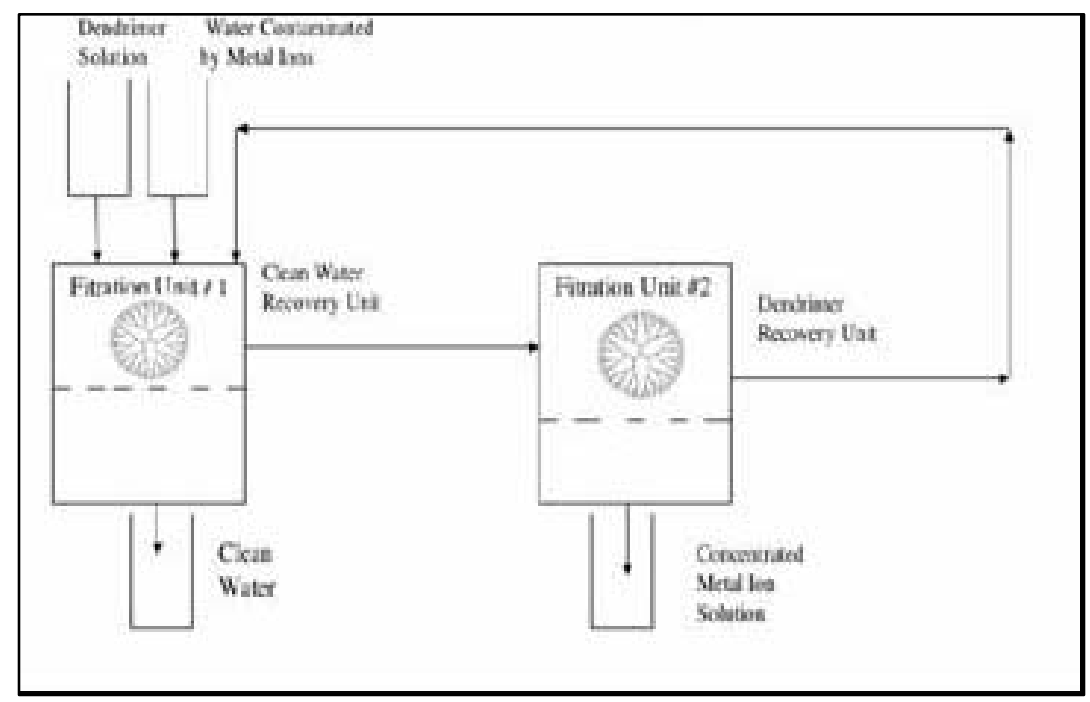

Figure 2. Recovery of metal ions from aqueous solutions by dendrimer-enhanced filtration

Nanoparticles (nanocrystals, carbon nanotubes, etc). A variety of nanomaterials are in various stages of research and development, each possessing unique functionalities that is potentially applicable to the remediation of industrial effluents, groundwater, surface water and drinking water (Table 2).

Single-Enzyme Nanoparticles (SENs): Due to their specificity and targeted effectiveness, enzymes may offer vast capabilities in the areas of chemical conversions, biosensing, and bioremediation (Durán and Esposito 2000). However, the lack of stability and relatively short catalytic lifetimes of enzymes may limit their usefulness as cost-effective alternatives to synthetic catalysts. Although methods such as enzyme immobilization, enzyme modification, and genetic modification have been used frequently to improve the stability and subsequent persistence of enzymes, nanotechnology has provided a new method whereby enzymes can be stabilized in the form of single-enzyme nanoparticles (SENs). The first SENs were assembled by Kim and Grate (2005), using chymotrypsin as a model enzyme. The synthesis of SENs involves enzyme surface modification, vinyl polymer growth from the enzyme surface (Watlington, 2005; Theron et al., 2008). Immobilized enzymes in biopolymers and carbon nanotubes are another strategy for environmental nanobiosensors (Pereira et al., 2008). 

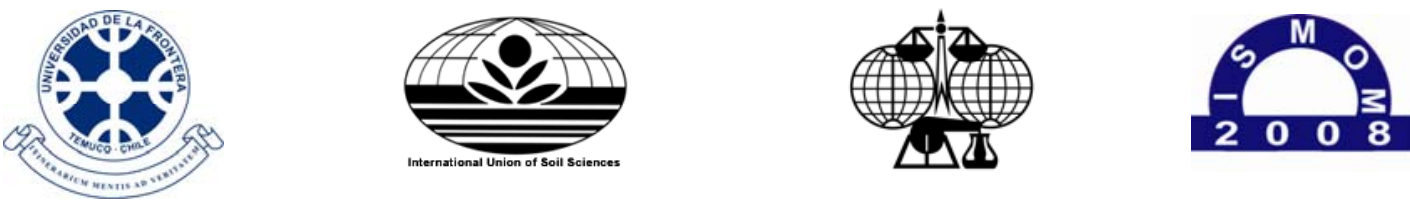

$5^{\text {th }}$ International Symposium ISMOM 2008 - November $24^{\text {th }}-28^{\text {th }}, 2008$ - Pucón, Chile

Keynote papers

Table 2. Examples of nanoparticles and nanomaterials for use in water remediation (Theron et al., 2008)

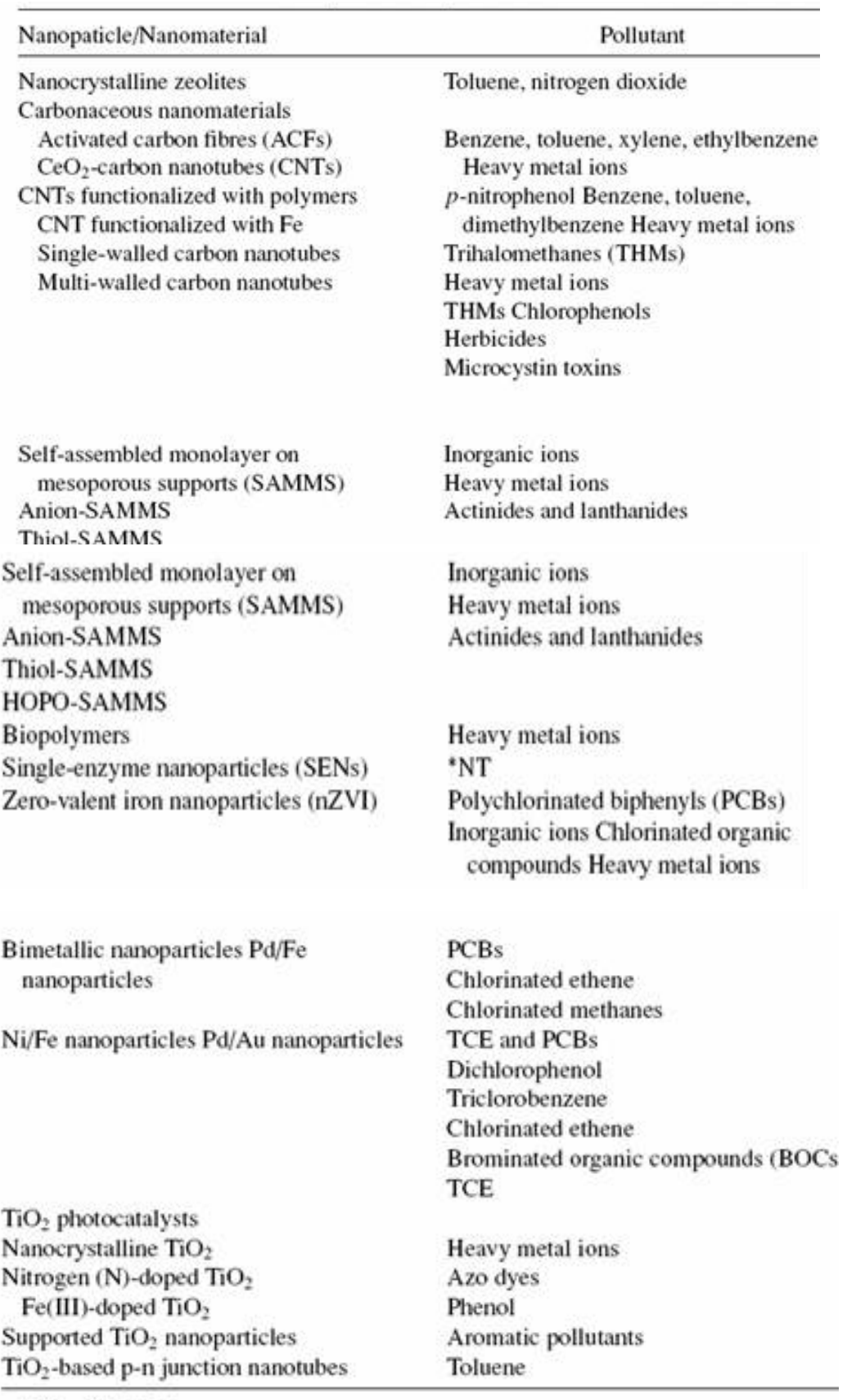

-NT - Not tested. 

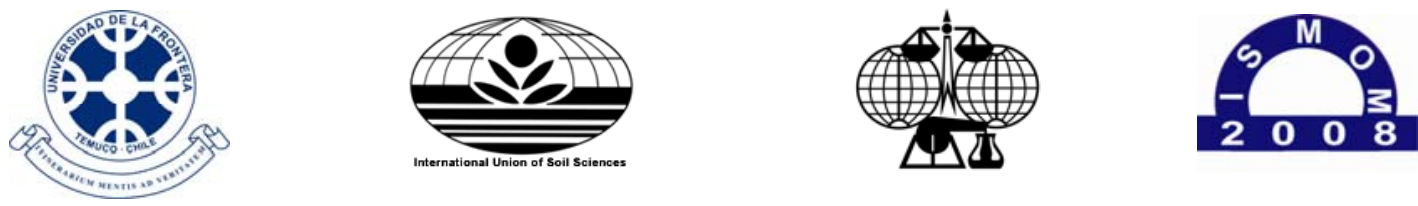

$5^{\text {th }}$ International Symposium ISMOM 2008 - November $24^{\text {th }}-28^{\text {th }}, 2008$ - Pucón, Chile

Keynote papers

\section{Nanotoxicity of Engineered Nanoparticles and Nanomaterials}

The use of engineered nanoparticles and nanomaterials for environment treatment, as discussed partially in the previous sections, has raised concerns for human exposure which dash from the absence of specific technologies orienting the removal of engineered nanomaterials from the water, and the safety of the new nanoparticles and nanomaterials that may be used by the water industry. These concerns are often based on its large mobility, small sizes, thus implying a greater potential for exposure as they are dispersed over greater distances and their persistence in the environment increases. However, few examples of nanomaterials treatment in the industrial chain of nanoparticles productions are published (Durán et al. 2007, 2008; Benn and Westerhoff, 2008). Some authors as Wiesner et al. (2006) suggested that smaller nanoparticles should not be very mobile, since their relatively large diffusivity would enable them to produce more frequent contacts with the surfaces of porous media such as groundwater aquifers or the sand filters used in potable water treatment. Consequently, Wiesner et al. (2006) concluded that there is no evidence to support the scenario of a new nanoparticulate contaminant that current water treatment infrastructure cannot handle. Many other researchers have contrary data, then, showing that this is still an open area for discussion.

\section{Conclusions}

It is clear from the literature that while much attention has been focused on the development and potential benefits of nanomaterials in water treatment processes, concerns have also been raised regarding their potential human and environmental toxicity. However, it is difficult to assess the effect of nanomaterials on health and the environment because the methods and tools for such a task have not been well developed yet (NNCO, 2006; Davies, 2007; Morris and Willis, 2007). It is extremely important that these processes be developed and investigated to ensure that nanomaterials are as safe as possible, while reaching their full potential. Once these information gaps were clear, it is certain that new nanomaterials, in water environment treatment, will play key roles in ensuring sufficient and good quality water and soil to meet the ever-increasing demand for potable water and safe soil in the agriculture (Tungittiplakorn et al., 2004; Mauter and Elimelech, 2008; Theron et al., 2008)

Acknowledgements: Support from FAPESP, CNPq, Brazilian Nanobiotechnology Network, Brazilian Carbon Nanotubes Network, Brazilian Nanocosmetics Network (CNPq/MCT) is acknowledged.

Keywords: Nanoparticles; bioremediation processes; nanotechnology.

\section{References}

Arkas, M., Allabashi, R., Tsiourvas, D., Mattausch, E-M., Perfler, R. Environ.Sci. Technol. 40, 2771-2777 (2006).

Bawa R, Bawa SR, Maebius SB, Flynn T, Wei C Nanomedicine: Nanotechnol.Biol.Med. 1, 150-158 (2005)

Benn, T., Westerhoff, P. Environ. Sci. Technol. 42, 4133-4139 (2008)

Davies JC (2007) EPA and Nanotechnology: Oversight for the $21^{\text {st }}$ Century; Woodrow Wilson International Center for Scholars:

Washington, DC.

Diallo,M. http://earth2.epa.gov/ncer/publications/workshop/pdf/10_20_05_diallo_mamadou.pdf (2005). 

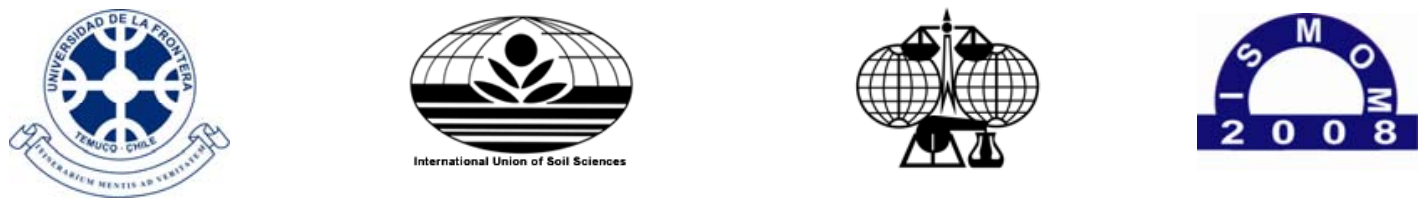

$5^{\text {th }}$ International Symposium ISMOM 2008 - November $24^{\text {th }}-28^{\text {th }}, 2008$ - Pucón, Chile

\section{Keynote papers}

Durán, N., Marcato, P.D., Souza, G.I., Alves, O.L. Esposito, E. J. Biomed. Nanotechnol,3, 203-208 (2007).

Durán, N., Marcato, P.D., Alves, O.L., Da Silva, J.P.S., De Souza, G.I.H., Rodrigues, F.A., Esposito, E. J. Nanoparticles Res. submitted (2008)

Durán, N., Esposito, E. Appl. Catal. B, Environ. 28, 83-99 (2000).

Kim, J., Grate, J.W. In ACS Symposium Series: Nanotechnology and the Environment: Applications and Implications, ed. B. Karn, T. Masciangioli, W. Zhang, V. Colvin, P. Alivisatos, 220-225. Washington, D.C. (2005).

Mauter, M., Elimelech, M. Environ. Sci. Technol. 9, 5843-5859 (2008)

Morris, J., Willis, J. U.S. Environmental Protection Agency Nanotechnology White Paper; U.S. Environmental Protection Agency: Washington, DC, February (2007).

NNCO-National Nanotechnology Coordination Office (Environmental, Health, and Safety Research Needs for Engineered Nanoscale Materials; (NNCO): Arlington, VA, September (2006).

Pereira A.C., Kisner, A., Durán, N. and Kubota, L.T. In Nanostructured Materials in Electrochemistry (A. Eftekhari, Ed). Wuley -VCH, New York, Chapter 5, p 243-265 (2008).

Savage, N., Diallo, M. J. Nanoparticle Res. 7, 331-342 (2005).

Theron, J., Walker, J.A., Cloete, T.E. Crit. Rev. Microbiol., 34, 43-69 (2008).

Tungittiplakorn, W., Lion, L.W., Cohen, C., Kim, J.U. Environ. Sci. Technol. 38, 1605-1610 (2004).

Watlington, K., U.S. Environmental Protection Agency, August 2005; www.epa.gov www.clu-in.org

Wiesner, M.R., Lowry, G.V., Alvarez, P., Dionysiou, D., Biswas, P. Environ. Sci. Technol. 40, 4336-4345 (2006).

Zhang, W.X. J. Nanoparticle Res. 5, 323-332 (2003) 